\title{
PROPP PORNO: LAS FABULOSAS CATEGORÍAS DE LA NOVELÍSTICA DE SILVIA C. CARPALLO
}

\author{
PORN PROPP: THE FABULOUS CATEGORIES \\ OF SILVIA C. CARPALLO'S NARRATIVE
}

PAOLA Bellomi

Università degli Studi di Verona

paola.bellomi@univr.it

\begin{abstract}
RESUMEN: La novelística porno y erótica sigue, en múltiples aspectos, los recursos propios de las fábulas, según la teorización de V. Propp, para construir su discurso narrativo; se trata de un discurso que muy a menudo intenta reglamentar y normalizar el escándalo que el sexo supone en nuestra sociedad heterodominante. La novelística de Silvia C. Carpallo servirá para reflexionar sobre la aportación que el género erótico está haciendo en la defensa o en el derrumbe de la ideología del poder dominante. Mi punto de vista se servirá de la perspectiva queer de la escuela italiana actual y, en particular, de las propuestas de los filósofos Michela Marzano y Lorenzo Bernini, en línea con J. Butler, A. Cavarero y M. Foucault. El propósito es reflexionar sobre las categorías de pensamiento que la literatura erótica española contemporánea está defendiendo y poner al descubierto sus mecanismos de ruptura o de conservación de la norma.
\end{abstract}

PALABRAS CLAVE: Vladimir Propp; Silvia C. Carpallo; literatura porno; literatura erótica; teoría queer; estudios pornográficos

ABSTRACT: Porn and erotic narrative has much in common with some narratological aspects of the fables, as Propp theorised in his study Morphology of the Folktale. The discourse that this production develops seems to be strongly normative because of the shock that sex produces in our hetero-dominant society. Silvia C. Carpallo's narrative will be a case-study in order to define the level of conservatism that the erotic genre has. In my analysis I will make reference to the queer perspective, in particular to the Italian school with philosopher such as Michela Marzano and Lorenzo Bernini, continuators of the philosophical reflections of J. Butler, A. Cavarero and M. Foucault. The aim is to reflect onto contemporary Spanish erotic literature and its categories of thought in order to determine the conservative or destructive character of the norm. 
Keywords: Vladimir Propp; Silvia C. Carpallo; Porn Literature; Erotic Literature; Queer Theory; Porn Studies

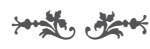

El potencial rompedor con el que se suele relacionar la narrativa erótica y la pornográfica, desde una visión más atenta, manifiesta en cambio numerosos aspectos conservadores; en la estructuración de los contenidos, muy a menudo la prosa que pertenece a estos géneros propone un esquema que parece reflejar el identificado por Vladimir Propp en su notorio ensayo sobre la fábula, Morfología del cuento (1974). Las treinta y una funciones que el lingüista ruso enumeraba en su estudio ${ }^{1}$ pueden detectarse fácilmente, por ejemplo, en las obras de Silvia C. Carpallo, periodista, sexóloga, escritora y sex blogger, como ella misma se define en su página web (<http://www.silviaccarpallo.com/>).

Carpallo es autora de dos novelas y dos colecciones de cuentos, publicados entre 2013 y 2016, con una frecuencia de uno cada año: Cincuenta escenarios para desatar tu pasión (2013, cuentos), El orgasmo de mi vida: un libro de sexo por y para todo tipo de mujeres (2014, cuentos), Decirte adiós con un te quiero (2015) y el reciente Si el amor te dijo "no" pregúntale otra vez (2016b). Los cuatro volúmenes están vinculados por un tema común: el sexo. Se trata de una producción que podría etiquetarse como "erotismo de autoayuda" (Illouz 2014), puesto que son obras que, como los manuales de desarrollo personal, se proponen profundizar en el autoconocimiento y en el bienestar de sus lectoras a través de los ejemplos positivos que se presentan en cada cuento o en cada capítulo. En este caso específico, se pretende liberar a la mujer de algunos tabúes relacionados con la esfera sexual, gracias a la presentación de varias figuras femeninas que, a partir de situaciones sentimentales no satisfactorias, a lo largo de la narración aprenden cómo mejorar sus vidas a través del descubrimiento y la superación de sus límites en materia de sexo.

Las obras de Carpallo se insertan en la corriente literaria que ha vuelto a recobrar lectores y espacio en las páginas de la prensa después del éxito (asombroso y quizá inesperado) de Cincuenta sombras de Grey, la trilogía novelesca romántico-erótica publicada en 2011 por la autora británica E. L. James (seudónimo de Erika Leonard Mitchell). ${ }^{2}$ La traducción al español de la trilogía fue

\footnotetext{
${ }^{1}$ Vladimir Propp proponía la noción de "función" como elemento narrativo fundamental del género breve: "Las funciones de los personajes representan, pues, las partes fundamentales del cuento, y son ellas las que debemos aislar en primer lugar. Para ello hay que definir las funciones. Esta definición debe ser el resultado de dos preocupaciones. En primer lugar, no debe tener nunca en cuenta al personaje-ejecutante. [...] Luego, la acción no puede ser definida fuera de su situación en el curso del relato. Hay que tener en cuenta la significación que posee una función dada en el desarrollo de la intriga. [...] Por función, entendemos la acción de un personaje definida desde el punto de vista de su significación en el desarrollo de la intriga" (Propp 1974: 33).

2 Para profundizar la comprensión del fenómeno comercial destallado con la publicación de la trilogía de E. L. James Cincuenta sombras en el contexto ibérico, se recomienda el interesante y
} 
publicada, en 2012, por la editorial Grijalbo, la misma que editó la antología de cuentos eróticos Cincuenta escenarios para desatar tu pasión, siete de los cuales están firmados por Silvia C. Carpallo. Cuando la autora española se asoma al mercado editorial, lo hace consciente de estar metida en un contexto favorable al desarrollo de su propuesta narrativa, como ella misma admite en una entrevista en la que se le preguntaba si se había aprovechado de manera deliberada del boom de la literatura erótica; Carpallo contesta: "Puede ser. Pero, ¿por qué va a estar mal aprovechar un momento de auge para hablar de algo de forma diferente? Cuando hay una oportunidad, hay que aprovecharla. No creo que sea ser una aprovechada, sino ser inteligente" (S.f. 2014: online).

Carpallo es periodista y sexóloga: esta mera descripción ayuda a definir algunas de las características de su obra, es decir el estilo, sencillo y directo, y el tema predominante, el sexo; es una mujer que tiene por tanto una formación en el campo de las letras y que se ha especializado en un área científica de ámbito médico. Todo esto, antes que confluir en sus escritos literarios, ha constituido el fundamento de su trabajo como bloguera. En la actualidad, participa como autora en el blog Eros de El País (http://blogs.elpais.com/eros/textos-silvia-ccarpallo/); este espacio virtual tiene como subtítulo "Sexy corner de El País" y se describe como "Ni enciclopedia ni consultorio sexual al uso. He aquí un rincón erótico festivo dedicado a las relaciones y la atracción entre seres humanos". Aparte de Carpallo, colaboran en el blog, coordinado por Analía Iglesias, otras cuatro mujeres: Anne Cé, Esther Porta, Venus O'Hara y Tatiana Escobar. Antes de la experiencia de este blog, la autora había colaborado con La Razón, publicando en el suplemento "A tu salud" la sección de "Salud sexual".

Las obras de Carpallo hablan de mujeres y están dirigidas claramente a un público femenino, como admite la propia autora en la entrevista que acompaña la presentación de su colección de cuentos El orgasmo de mi vida; cuando el entrevistador le pregunta si el libro es para mujeres, ella contesta:

Sí. Siendo sincera, me cuesta mucho pensar desde el punto de vista masculino. Creo que es algo que me queda por alcanzar: conocer cómo funciona la sexualidad masculina. Por mucho que hable sobre sexo y sexualidad con los hombres, me cuesta mucho imaginar lo que sienten. Es cierto que el libro es sobre mujeres y está escrito por una mujer, pero eso no quiere decir que los hombres no lo puedan leer o que no puedan excitarse en determinadas escenas. (S.f. 2014: online)

Desde un punto de vista ontológico, ¿qué quiere decir hoy, en el siglo xxI, que se trata de libros para un público femenino? ¿Y qué relación existe entre el género del autor - de la autora, en este caso-y sus personajes de creación? La lectura y el estudio de la narrativa de Carpallo puede ayudar a reflexionar sobre los conceptos de género e identidad sexual y sobre el estatuto contemporáneo

divertido estudio de Rafael Núñez Florencio, en el que también se reflexiona sobre los conceptos de "boom literario", de "género" y de "literatura" en relación con las vertientes erótica y pornográfica (Núñez Florencio 2013). 
de la mujer a través del espejo (¿deformante?) de la literatura erótica o pseudopornográfica que aquí se comenta. ${ }^{3}$

Si se acepta como correcta la definición que el DRAE da del sustantivo pornografía, o sea una "presentación abierta y cruda del sexo que busca producir excitación", las obras de Silvia C. Carpallo pueden insertarse en esta categoría, más quizá que en la de la literatura erótica, que, según el Diccionario, se define como "dicho de una obra o de un género literarios o de otro tipo: que tratan del amor sensual o el deseo amoroso". Las descripciones de los actos sexuales o de los deseos y sueños eróticos de las protagonistas de El orgasmo de mi vida y de Si el amor te dijo "no" pregúntale otra vez no dejan espacio a la imaginación, son deliberadamente directas y explícitas y quieren provocar la excitación en las lectoras.

Antes de seguir con la reflexión que aquí estamos abarcando sobre el alcance de estas obras, es interesante anotar la posición de Carpallo frente a la pornografía, en particular la cinematográfica. En opinión de la autora, tanto el porno como la literatura erótica constituyen actualmente la fuente principal de la educación sexual de muchas personas, que se forman por tanto a través de imágenes estereotipadas y ficcionales y desarrollan su vida sexual midiéndose con el modelo que este tipo de producción presenta. Lo cual, afirma Carpallo, es preocupante:

Me preocupa que el cine porno, al igual que la literatura erótica, sea ahora mismo nuestra educación sexual. Podríamos debatir sobre el rol del hombre y de la mujer en este género de cine, pero lo peor es que la gente se educa sexualmente viendo pornografía. Esto no es bueno porque se crean unas expectativas que no tienen nada que ver con la vida real. [...] No estoy a favor de que se elimine el cine porno, sino de que entendamos que es ficción y juguemos con ello como otra herramienta más para usar en un momento de excitación. El cine porno no puede ser una herramienta para entender qué es la sexualidad. (S.f. 2014: online)

En 2016, Carpallo vuelve a reflexionar sobre el tema, esta vez en calidad de periodista del blog Eros, en una entrevista a Erika Lust, directora de cine porno que, en la presentación de su página web, se define como "una feminista prosexo" (http://erikalust.com/). Lust, nacida en Suecia, se formó en ciencias políticas, feminismo y sexualidad; después de la carrera, se mudó a Barcelona, donde empezó su carrera en la industria del cine explícito; por tanto, nos encontramos con otro ejemplo de una mujer que tiene un alto nivel de instrucción, y con una formación específica en temas relacionados con la esfera femenina y el sexo. Sin embargo, no hay que olvidar que la formación universitaria, al igual que los otros aparatos educativos, está insertada en un sistema institucional y político que

\footnotetext{
${ }^{3}$ Rafael Núñez Florencio pone en tela de juicio definiciones que normalmente se relacionan con las novelas de ese estilo, como las de mummy-porn, o porno para mamis, porno romántico y sexo de mesa camilla (Núñez Florencio 2013: 28 y 30).
} 
intenta reglamentar las formas y los contenidos pedagógicos (Bernini 2013: 30). ${ }^{4}$ Los individuos allí formados casi seguramente reproducirán lo aprendido en la institución académica también en su vida profesional y en la privada; es, por otra parte, importante recordar que la universidad participa en la conservación de modelos sociales y culturales tradicionales y que el espacio de innovación y de libertad hay que reclamarlo siempre y en voz alta.

A pesar de tener un historial parecido, Carpallo y Lust tienen dos perspectivas diferentes frente a la pornografía como medio artístico para la liberación de la mujer, como se transparenta del siguiente intercambio de preguntas (de Carpallo) y respuestas (de Lust):

Carpallo: Es consabido que el cine porno tiene un gran impacto en la sexualidad de las personas, ¿un porno femenino ayudaría a hacer más diversa la sexualidad?

Lust: No femenino, jfeminista! Obviamente tengo una mirada femenina, por algo soy mujer, pero no me cansaré de repetir que yo no hago porno para mujeres, sino porno para personas que quieren explorar la sexualidad de ambos sexos de forma pasional, elegante y respetuosa. Esto comulga con los valores feministas, que intentan poner a la mujer a la misma altura que el hombre, cosa que en el porno se traduce como tener en la misma consideración el placer de ambos. Bajo estos valores, está claro que puede construirse una sexualidad mucho más diversa y enriquecedora, donde se puedan representar todo tipo de cuerpos, razas y personalidades sin caer en estereotipos caducos.

Carpallo: Igualmente se suele hablar de que el porno da una imagen muy negativa de la mujer, ¿se pueden cambiar esos clichés y seguir excitando tanto a hombres como a mujeres?

Lust: Por supuesto. [...] Si eliminamos estos clichés, como tú los llamas, las posibilidades son infinitas: historias, personajes, localizaciones, recursos visuales, músicas... Todo en favor del feminismo "sex positive", es decir, algo respetuoso que recoge la sensualidad, la lujuria, el deseo y la pasión de un encuentro sexual memorable. (Carpallo 2016a: online)

Lust aboga por una lucha para la liberación de la mujer que pase a través de la apropiación de un género principalmente masculino (y machista), el cine porno, para conquistar un nuevo espacio que dé una nueva voz tanto a la perspectiva femenina como a la del hombre. Se trata de una redifinición ideológica,

\footnotetext{
${ }^{4}$ En el presente estudio fundamento mis reflexiones en particular en las líneas teóricas de la actual escena filosófica italiana, que está desarrollando un profundo trabajo de cuestionamiento de los cánones estéticos, lingüísticos y culturales relacionados con las políticas de la sexualidad. Vinculo por tanto los estudios de la escena española e internacional representada por pensadores como Paul B[eatriz] Preciado (2002) y Virginie Despentes (2007), con los de filósofos como Adriana Cavarero, Lorenzo Bernini y Michela Marzano. Para una introducción a estas nuevas perspectivas, véanse los trabajos del centro de investigación "Politesse. Politiche e Teorie della Sessualità" (http://www.politesse.it/ y http://www.dfpp.univr.it/?ent=bibliocr\&id=200. Última visita: 22.11.17) y el recién publicado volumen de Bernini sobre el panorama de las teorías queer y la bibliografía actualizada allí incluida sobre este tema (Bernini 2017).
} 
no solo estética, de los papeles sociales de los sujetos masculinos y femeninos. Carpallo prefiere en cambio emplear el género erótico como una vía de acceso para educar a las lectoras (y quizá, también algún lector) en materia sexual:

Creo que hay que aprovechar que se ha acercado un nuevo público a estas novelas, mujeres de toda clase y condición, para hacer un poco de educación sexual desde este tipo de producto cultural. Hablar de diversidad sexual, de otros tipos de relación, del autoconocimiento, del empoderamiento femenino, de la necesaria revolución sexual del hombre y de otros muchos aspectos, más allá del látigo y la fusta. Al menos, es lo que yo intento. (León 2015: online) ${ }^{5}$

Tanto Lust como Carpallo subrayan el derecho de la mujer a la autodeterminación, pero en el caso de la directora de cine, se trata principalmente de un cambio que pasa por la resignificación del medio. La filósofa Emiliana Galiani define la pornografía, en perspectiva foucaultiana, es decir como una práctica cultural cuyos procesos de interpretación contribuyen a la construcción de los sujetos sociales y de su identidad; esto significa que el porno produce efectos políticos en sus destinatarios, ya que propone unos modelos comportamentales que reproducen unas formas de poder, las cuales están basadas en la sumisión del cuerpo femenino, " $y$, así haciendo, constituyen de manera deliberada una identidad social y sexual subordinada" (Galiani 2011: 251). ${ }^{6}$ La filósofa italiana se pregunta si esta relación de subordinación entre hombre y mujer pertenece al género pornográfico o si es, a su vez, un resultado de un sistema de dominación más general, de un mecanismo de control que caracteriza toda la organización social. Entonces, como propone Lust, ¿es suficiente apoderarse del medio de coacción -el cine porno- y re-semantizarlo en clave feminista para romper con los mecanismos de sumisión? ¿O es a través de la propuesta de ejemplos positivos y tranquilizadores, como lo son las protagonistas de las obras de Carpallo, que se puede llegar a una educación sexual que rompa con los estereotipos sociales y permita la concienciación, a través del erotismo, de las propias mujeres?

La propuesta literaria de Carpallo nos sugiere varias reflexiones, empezando por el valor -positivo o negativo- que puede tener el proceso de normalización al cual están sometidas las figuras que se mueven en las páginas de su narrativa. De manera muy sintética, y por tanto con lagunas, se podrían resumir las historias que se cuentan en El orgasmo de mi vida y en Si el amor te dijo "no" pregúntale otra vez como las aventuras de una serie de protagonistas femeninas, de diferentes edades, pero todas pertenecientes a una clase burguesa más o menos acomodada, que se sienten por algún motivo insatisfechas de sí mismas o de la situación familiar o laboral en la que se encuentran. Cada historia termina de manera positiva, con la resolución de la quest, después de haber pasado por algunas pruebas difíciles.

\footnotetext{
${ }^{5}$ Es curioso notar que los titulares que se emplean en las entrevistas a Carpallo muy a menudo hacen referencia directa a la pornografía, aunque luego en el texto se hable de manera preponderante de educación sexual (S.f. 2014; León 2015).

6 Las traducciones del italiano al español son mías.
} 
Con su narrativa, Carpallo se propone presentar unos modelos femeninos con los que las lectoras se puedan identificar y que quieran reproducir en su vida real. Las mujeres que protagonizan estas historias, al final, llegan a ser personas más ricas emotivamente $y$, en teoría, más conscientes de sí mismas y de su potencial. Este cambio profundo se da a través del sexo, que las protagonistas experimentan en sus diferentes variedades, desde el sexo extra-conyugal al sexo lésbico, desde el triángulo al auto-erotismo, desde el sexo virginal al BDSM. En apariencia, se trata de ejemplos de ruptura de las costumbres sociales, que han obligado durante muchos siglos a ver a la mujer como madre y esposa, sin tener la libertad de gozar de su vida sexual, que estaba exclusivamente orientada a la procreación y a la satisfacción del hombre. ${ }^{7}$ Es notorio que en las sociedades occidentales contemporáneas se ha intentado disimular o eliminar -callándolas- las diferencias sexuales, reivindicando una presunta igualdad de todos los individuos delante de la ley (Bernini 2013: 17); está claro que la negación de la diversidad a través de la búsqueda de la normalización conlleva una mayor estabilidad social, pero también conduce a un mayor grado de homogeneización.

Las protagonistas de las obras de Carpallo juegan con su sexo y con el de su compañero, abren cremalleras, entran con sus manos en los pantalones de los hombres que desean, etc., o sea, demuestran una actitud positiva y activa frente a la relación meramente física. Y, sin embargo, no logran salir del marco social en el que la mujer sigue estando confinada. Como se ha recordado, una acusación frecuente que se dirige al porno es la imagen sumisa de la mujer que este género sigue reproduciendo, como si se tratara de una muñeca o de un objeto sexual a disposición del hombre. La postura que los personajes femeninos de Carpallo asumen debería devolver la dignidad a estos sujetos, ya que son ellas quienes deciden sobre su vida, tanto en lo que se refiere a la esfera emotiva como a la

\footnotetext{
7 En el estudio de Núñez Florencio sobre la oleada de libros eróticos y porno-románticos que ha invadido las librerías en esta década, se subraya como una de las características de esta producción es el proceso de normalización a las que se han sometido algunas prácticas sexuales hasta hace muy poco consideradas marginales o incluso tabú, y que hoy, en cambio, han entrado en la categoría -mucho más tranquilizadora- de "juegos eróticos". Sin embargo, nota Núñez Florencio, la transgresión que se propone en estas novelas es superficial: "Tras la epidermis de la transgresión -por otra parte hoy en almoneda- late como mínimo una obvia desigualdad cuyas consecuencias no son difíciles de calibrar para todo aquel que se resista al embeleco. En estos relatos, de manera sistemática, él decide y ella asiente. Él es dominante y ella sumisa. [...] Pero hurtaríamos al debate un detalle esencial si no reveláramos la perspectiva desde la que se presenta el proceso: quien relata en primera persona su ¿ascenso?-¿descenso? al universo sadomasoquista no es un alma torturada que busca nuestra comprensión sino una chica normal y corriente, liberada, alegre, una mujer de su tiempo, culta, moderna, profesional" (Núñez Florencio 2013: 32). Junto con Núñez Florencio, me pregunto hasta qué punto se pueda compartir la interpretación que algunos sociólogos han dado acerca de este fenómeno cultural y literario, es decir de la representación de la violencia en un contexto ficcional como un "modo eficaz de exorcizar a la misma en la realidad. La teatralización de sometimientos, torturas y violaciones vendría a ser de este modo la prueba palpable de que tales acciones han dejado de ser un peligro en la sociedad en que vivimos" (Núñez Florencio 2013: 33). Otra constante que el estudioso identifica en esta producción es que "estos libros están escritos por mujeres" (2013: 32); sin embargo, considero que en este sentido habría que matizar un poco más la cuestión de la autoría femenina de los libros eróticos o soft-porno como son los que aquí tratamos porque es frecuente el uso de pseudónimos en este género de literatura $y$, a veces, detrás de un nom de plume femenino podría esconderse un autor masculino. Para un somero acercamiento a la cuestión de los seudónimos en literatura, véase el volumen de Carmela Ciuraru Nom de Plume: A (Secret) History of Pseudonyms (2012).
} 
física. Pero, mirando más atentamente, estas protagonistas "modélicas" en realidad no rompen con los esquemas sociales preestablecidos ni proponen una identidad femenina concretamente renovada.

Si una de las finalidades que mueven a Carpallo es llegar a una mayor concienciación de la mujer a través también de los modelos femeninos que ella crea en su obra, el objetivo se cumple solo a medias puesto que la autora no sale de un vicio ideológico que sigue vivo en nuestra sociedad: no considera -al parecer- que "aceptar el concepto de mujer significa aceptar la lógica masculina de la heterosexualidad" (Restaino 2002: 66). La identidad femenina es ella también un resultado de la tradición cultural de la sociedad, con lo cual, quedándonos en el ámbito occidental al que las protagonistas de Carpallo pertenecen, habría que cuestionar ante todo la definición y los límites del concepto de "mujer", para desmontar su arquitectura desde dentro.

De acuerdo con Adriana Cavarero, la mujer no tiene un lenguaje propio, no existe una lengua materna porque no existe una lengua de la mujer, ya que durante muchos siglos ha sido la lengua del padre la que ha construido la imagen femenina: "La mujer no tiene un lenguaje propio, más bien usa el lenguaje del otro. Ella no se autorrepresenta en el lenguaje, sino acoge las representaciones de sí misma producidas, a través del lenguaje, por el hombre" (Cavarero 1987: 52). La generación de mujeres que está trabajando en la pornografía ${ }^{8}$ propone unos planteamientos nuevos sobre el concepto de identidad femenina, su representación y su lenguaje. Apoderarse de un género reconocido hasta hoy como machista, como lo es el porno clásico, significa aceptar un desafío que va hacia el desmontaje de estos esquemas culturales y sociales (Sarracino y Scott 2008). Esta operación de ruptura pasa por una fase de desvelamiento de la máscara y otra de fundación de un nuevo lenguaje que realmente permita dar voz a la mujer. En cierto sentido, el discurso pornográfico que las directoras como Erika Lust están desarrollando es heredero de las reivindicaciones que grupos de activistas como Queer Nation llevaron a cabo en los años noventa, es decir reclamar su derecho a expresar libremente su identidad, sin las rejas de las jaulas de tolerancia que la sociedad burguesa requería para encerrar las minorías sexuales (y sus diversidades) dentro de un perímetro tranquilizador:

En lugar de tranquilizar la opinión pública a través de la promoción de una imagen conformista de las minorías sexuales [...] los activistas de Queer Nation-operando, como diría Butler, una "reconversión de la abyección en acción política"- eligieron presentarse como una amenaza para la respetabilidad y el

\footnotetext{
${ }^{8}$ En el ámbito italiano, véase por ejemplo la experiencia-experimento del colectivo Le ragazze del porno, que reúne doce directoras y guionistas de cine. El proyecto, llevado a cabo en 2016, después de dos años de trabajo, tenía como objetivo la creación de una colección de cortometrajes porno de autor. En la presentación del proyecto se afirmaba: "En Italia en particular se necesita ampliar el punto de vista sobre la sexualidad y sobre su belleza sin distinción de género y orientación sexual e de manera independiente de los cánones estéticos impuestos. Creemos que el deseo puede tomar múltiples formas y queremos finalmente estar libres de representarlas para gozar de ellas, todas y todos. Sin censuras, cada director eligió una estética, un punto de vista trabajando sobre fiction, gonzo, documental y videoarte" (<https://igg.me/at/leragazzedelporno/ x>; última visita: 30.1.2017).
} 
vivir tranquilo burgués y prefirieron para sus manifestaciones un estilo provocador, agresivo y paródico a la vez. [...] No para obtener islas de tolerancia en la sociedad, sino todo lo contrario: para hacer de cada espacio social "un espacio lésbico y gay". (Bernini 2013: 27) ${ }^{9}$

Cierto conformismo que se nota en la narrativa de Carpallo no contribuye a una mayor concienciación, sino a una aceptación pasiva de las dinámicas patriarcales. Por ejemplo, en una escena de Si el amor te dijo "no" etc., se describe cómo Alejandra decide acostarse con su jefe, a pesar de la diferencia de edad (él es menor que ella) y de estar casada. Supuestamente es ella quien da el primer paso:

\begin{abstract}
Daniel lanza una moneda al aire $y$, antes de que me desvele el resultado, me lanzo sobre él y comienzo a besarle con el hambre de toda una vida. Él se muestra sorprendido al principio, pero pronto me corresponde tal y como esperaba. [...] Daniel me empotra contra la pared y dejo que me arrincone, que me haga suya, que me libere de toda mi ropa, de todos mis corsés. [...] Daniel me pone ahora sobre la mesa y me dejo embestir por él, como si en cada empujón inyectase un poco de vida en mí. Comienzo a gritar, a gemir, a morder, a gimotear. El orgasmo no se hace esperar, explota en mi vagina, pero se expande por absolutamente cada poro de mi piel, me libera. Daniel también explota, rápido, fuerte, para después caer rendido sobre mí. (Carpallo 2016: edición Kindle)
\end{abstract}

A pesar de ser Alejandra quien da el paso a la acción, es Daniel quien la dirige: es el hombre quien da el ritmo a la escena y a la cópula; el placer de la mujer está subordinado a las decisiones de Daniel, dependen de él: el hombre la empotra, le quita la ropa, la pone sobre la mesa, etc. Y, sin embargo, con respecto a las escenas del cine porno, aquí es la mujer la que llega al orgasmo antes que el hombre, con lo cual se puede vislumbrar un mayor equilibrio entre los dos ejes de la pareja. Pero en esta aparente igualdad se puede ver otro peligro que amenaza la lucha de liberación de la mujer, es decir, la complementariedad entre identidad masculina e identidad femenina; citando a Cavarero (2002: 85), la subordinación se ve sustituida por la complementariedad, el conflicto por la armonía, pero en realidad no asistimos a un verdadero cambio en la manera de concebir las identidades, que siguen siendo percibidas según una perspectiva dual y binaria. Lo masculino y lo femenino que se representan en las novelas de Carpallo siguen en el marco del imaginario androcéntrico, pero en su versión más moderna y tranquilizadora; en esta complementariedad normalizadora, la mujer sigue siendo la parte más emotiva y dependiente, frente al hombre, que sigue siendo el garante de la racionalidad y de la acción.

\footnotetext{
${ }^{9}$ De este volumen de Lorenzo Bernini existe una traducción al español a la cual, lamentablemente, no he tenido acceso; para el lector interesado, señalo en la bibliografía esta edición también, de 2015, que tiene un apéndice inédito titulado "Autorretrato de un investigador queer en la ciudad de Romeo y Julieta".
} 
En las novelas de Carpallo se juega con el límite entre la pornografía y el erotismo: las descripciones explícitas, detalladas y hasta quirúrgicas quieren enseñar el cuerpo, con un intento de liberación de la sexualidad, a la vez que cumplir con la finalidad didáctica que está en la base de estas narraciones. En el episodio titulado "Orgasmo 2. Agnes" (El orgasmo de mi vida), por ejemplo, la lectora lee la descripción que Agnes hace, escondida, de la escena de sexo entre su amiga Judith y un desconocido; la voz narrativa describe la acción del siguiente modo:

Sus cuerpos están como enredados, están de rodillas en la cama, él detrás de ella. Judith ha echado la cabeza sobre su hombro, y mientras él la besa, acaricia sus pechos, los coge con ambas manos, los aprieta. Las manos de ella están en el pene de él, y suben y bajan sobre su tronco, mientras el inglés gruñe y se restriega contra ella. Las manos de él ahora bajan por el vientre de mi amiga para perderse después entre sus piernas. (Carpallo 2014: edición Kindle)

La narrativa de Carpallo es semi-pornográfica no en el sujeto representado (el sexo explícito), sino en el uso narrativo y semiótico que se hace de él. Citando a la filósofa italiana Michela Marzano:

\begin{abstract}
Nuestra hipótesis es que la pornografía no llega en absoluto a enfrentarse con el problema de la sexualidad en sus aspectos oscuros, como en cambio hace el erotismo, puesto que, al intentar poner en escena los aspectos más escondidos y olvidados de la vida humana, vacía de su contenido el misterio de la sexualidad: al querer representar los fantasmas masculinos y femeninos, los reduce a simples productos de consumo; al meter el cuerpo en primer plano, impide que el deseo emerja. (Marzano 2012: 3)
\end{abstract}

En las novelas de Carpallo es la cáscara retórica empleada por la autora la que revela que el calificativo "pornográfico" se aplica más bien al producto cultural que la lectora tiene en su mano, que a los contenidos en sí. Delante de las escenas de sexo descritas en estas obras, da la impresión de que se trata de un escamoteo para vender un producto de consumo, más que literario, a través de la sexualización de la narración. En la opinión de Marzano, la pornografía se presenta a menudo como un arte o una ciencia del conocimiento, puesto que, a través de la visión o descripción minuciosa del cuerpo y de los órganos sexuales, pretende desvelar "los secretos del placer" (Marzano 2012: 3). Desde esta óptica, la escritura de Carpallo es porno, ya que, con sus representaciones de las escenas de sexo casi de guion cinematográfico, se propone favorecer unas enseñanzas que, supuestamente, las lectoras de este género de literatura desconocen por completo o casi. La escritura narrativa de Carpallo tiene mucho en común con otra reflexión sobre la pornografía propuesta por Marzano en su ensayo La fine del desiderio. Riflessioni sulla pornografia:

La pornografía no es subversiva. Claro, se viste de rebelión y pretende oponerse a cualquier forma de "represión" del sexo. Pero lo hace con la única finalidad de camuflar la consolidación de un sistema de control que niega la intimidad 
de la sexualidad humana. Se declara partidaria de la omnipotencia del deseo, pero solo para decretar su fin. (Marzano 2012: 4)

También en las obras de Carpallo se proponen unos personajes cuya función parece ser la de rebelarse contra la sumisión y la represión de las costumbres sexuales femeninas. La subversión que pretenden encarnar tanto la pornografía más casera (estoy pensando en la autoproducción de imágenes y materiales audiovisuales que se encuentran gratuitamente en la web), como la sexualidad explotada por Carpallo, si se mira más de cerca, revela en cambio la homologación de estos géneros a la norma dominante, los excesos que se muestran o describen en nada ayudan a derribar ciertos tabúes o a combatir los estereotipos.

Se puede suponer que la lectura de los detalles físicos en las escenas en las que el sexo -imaginado o gozado por los personajes- es el elemento narrativo preeminente tendría que suscitar el deseo en la lectora. Sabemos que la relación entre pornografía y cuerpo es claramente fundamental. La descripción de las prácticas sexuales tiene, entre sus finalidades, la de despertar y alimentar la fantasía y la curiosidad de quien lee. Pero, ¿qué es lo que revelan estos detalles reiterados y repetidos? En la insistencia en la descripción de los cuerpos, Marzano identifica el exceso de realidad que caracteriza la pornografía, que niega la elipsis y busca la hipérbole en la representación que hace del sexo; pero esto, afirma la filósofa, "niega no tan solo cualquier intento personal de encontrar una vía de acceso para el deseo, sino el deseo mismo, es decir lo que define nuestra humanidad" (Marzano 2012: 5). La hipérbole en las obras de Carpallo se da en la necesidad que las protagonistas demuestran de llegar al orgasmo, de satisfacer su deseo sexual, para sentirse libres, para volver a la vida, para sentirse completas, etc. A pesar de cierta retórica romántica que se emplea en la narración, estos personajes viven sus relaciones como si fueran autómatas, están programados para cumplir con unas acciones que serían: encontrar a alguien que les satisfaga a través del sexo y no importa mucho quién sea este "alguien". Casi siempre, en estas historias, se trata de encuentros fortuitos con hombres; el lesbianismo aparece solo como experiencia "alternativa", o bien como un episodio único, no programado y consecuente con una borrachera, o bien como elemento complementario al clásico triángulo hombre-mujer-mujer. En definitiva, los modelos de relaciones sexuales que se proponen permanecen en el marco heterosexual.

Marzano define a los personajes de la pornografía como a muñecos, objetos que se dejan manipular y que pierden cualquier característica individual y original (Marzano 2012: 17). Los personajes de Carpallo son, en este sentido, como muñecos o tipos. En la pornografía, "el individuo es tan solo un pretexto: ya no es insustituible ni único, sino es intercambiable y ya no difiere de un objeto" (Marzano 2012: 21). En las narraciones de Carpallo pasa algo parecido. En estas novelas, no se trata de la anulación de los cuerpos, sino que son las relaciones las que son intercambiables. Al analizar las dinámicas que crean la situación sexual, se puede notar que en la mayoría de los casos se trata de un esquema fijo en el que una mujer -la protagonista de un episodio concreto- se 
siente profundamente insatisfecha con su vida, pero el encuentro casual con un hombre le devuelve la felicidad y las ganas de vivir. Sin embargo, es el azar el que elige qué hombre se le presenta delante $y$, en ninguno de los casos que forman el catálogo amoroso de Carpallo, las mujeres rechazan al individuo que se le ha manifestado delante de los ojos. La impresión es que estas figuras masculinas podrían ser las mismas o totalmente diferentes, pero las figuras femeninas reaccionarían del mismo modo, es decir deseando con pasión que la relación con el hombre las liberara de las cadenas de la rutina cotidiana.

Si la sexualidad es el espacio para el estupor y la pornografía es el espacio de los estereotipos (Marzano 2012: 23), la propuesta narrativa de Carpallo es una mezcla de los dos elementos; por un lado, las protagonistas se dejan llevar por el asombro, la curiosidad y la fantasía (sexual); por otro lado, las parejas que se crean vuelven a proponer los clichés de nuestra sociedad. Como en el porno, también en esta narrativa se nota que cada acción, cada gesto sirve para algo, según la ley de la utilidad. Como en la teoría de Propp, sabemos que "actos idénticos pueden tener significaciones diferentes, y a la inversa. Por función, entendemos la acción de un personaje definida desde el punto de vista de su significación en el desarrollo de la intriga" (Propp 1974: 33).

Cada protagonista de estas novelas -que correspondería a la figura del héroe según la nomenclatura de Propp- parte de una situación inicial de insatisfacción y cumple una serie de acciones para poder llegar a cambiar este escenario: una vuelve a trabajar, después de haber pasado toda su vida como ama de casa y su liberación pasa no tanto por la independencia económica, sino por la traición a su marido con su joven jefe; otra decide que ya es tiempo para perder la virginidad y se busca a un chico de quien enamorarse para cumplir con su propósito; otra determina aceptar la invitación de una amiga para participar en unas sesiones de sexo BDSM, etc. Cada acción sirve para llegar a la realización del fin último de la búsqueda, el goce amoroso. Si las protagonistas parecen sorprenderse de su audacia y de las imprevistas relaciones sexuales que la vida les regala, en quien lee el efecto no es el mismo sino el contrario; muy poco se deja a la imaginación del lector: cada escena está tan estructurada y los personajes están tan perfilados que es muy difícil dejarse sobrecoger. ${ }^{10}$ De acuerdo con Marzano (2012: 37), el riesgo que corren los productos relacionados con la sexualidad es que, por aspirar a explorar todos los placeres posibles, se vuelvan monótonos y repetitivos.

Además, la rigidez compositiva de estas obras no contribuye a romper las costumbres sociales, sino que recoge los estereotipos del mercado y los reitera. Esto está clarísimo, por ejemplo, en la colección de cuentos El orgasmo de mi vida, aparecido en 2014, un año después de la anterior antología, Cincuenta escenarios para desatar tu pasión, que había sido publicada por la misma editorial que había editado, en 2012, la traducción al español de Cincuenta sombras de Grey. ${ }^{11}$

\footnotetext{
${ }^{10}$ No comparten esta opinión las comentaristas de los volúmenes de Carpallo en las páginas de venta en Amazon.

${ }^{11}$ No es una casualidad que el primer cuento de El orgasmo de mi vida proponga como modelo
} 
La elección de la editorial no es secundaria en la reflexión sobre el género narrativo que aquí se está tratando. La primera colección de cuentos, como se ha visto, está vinculada al éxito de la novela anglosajona de James; la editorial Grijalbo aprovechó la notoriedad de la trilogía para publicar un volumen con un título que hacía una clara referencia a Cincuenta sombras de Grey y que, encima, se vendía junto con una corbata negra y unas esposas. En este caso, la idea de libro como producto de consumo es patente. La segunda colección de cuentos de Carpallo, El orgasmo de mi vida, se publica en la barcelonesa Lectio Ediciones en la colección Entre paréntesis, que se define como una colección de "Novelas con alto contenido erótico que se inspiran en la vida real para dar lugar a la fantasía" (<http://www.lectio.es/coleccions.php?cat=9>). Entre los títulos, aparecen La concubina perfecta, de Chloë Thurlow, y la serie Ruborízate, Ruborízate de nuevo y Ruborízate aún más, de Marie Gray. La mayoría de las cubiertas proponen un (ab)uso clásico del cuerpo de la mujer como objeto sexual cuya imagen ayuda a la venta de un número mayor de copias (Zanardo 2010). Aparte del volumen de Carpallo, que emplea un dibujo con la cara de una joven mujer en primer plano, los demás libros de la colección muestran pedazos de cuerpos femeninos, descuartizados en la instantánea fotográfica: unas piernas perfectas, con unos zapatos de tacón rojos y tanga negro; el cuerpo de una joven que enseña sus pechos y su boca abierta, con los labios pintados de rojo, que se ofrece a la visión del observador, etc. Está claro que la editorial ha optado por una sexualización del cuerpo de la mujer con fines comerciales: como en el porno, se reduce el sujeto femenino a objeto y se publican en primer plano cuerpos que se ofrecen a la vista, sensuales y eróticos, disponibles siempre y con promesas de goce infinito. Un uso de la imagen femenina de este tipo no favorece la lucha en contra de los estereotipos a los que la mujer está sometida. ${ }^{12}$ Sin embargo, la otra editorial que ha publicado las dos novelas de Carpallo, Decirte adiós con un te quiero y Si el amor te dijo "no" pregúntale otra vez, Versátil Ediciones, también de Barcelona, propone otro mensaje: ambas obras pertenecen a la colección Versátil romántica, que publica novelas de amor, pasión, erotismo y sonrisas, según las etiquetas que se emplean en la web de la editorial (<http://www.ed-versatil.com/web/producto/versatil-romantica-2/>). Versátil ha elegido una presentación tipográfica irónica, alegre y coloreada, muchas veces se emplean dibujos o fotos de paisajes $y$, en los casos de imágenes con sujetos femeninos, el cuerpo de la mujer no se muestra de manera excesivamente sexualizada (no hay ningún desnudo ni "descuartizamiento" sexual del cuerpo). Por lo que se refiere a las novelas de Carpallo, solo en la primera se anuncia en la cubierta que se trata de "un erotis-

femenino a una mujer que, insatisfecha de sí misma, se deja llevar por la curiosidad por el mundo BDSM y, en esta dimensión, encuentra por fin su satisfacción. El guiño a la trilogía de E. L. James es patente, aunque la narrativa de Carpallo en ningún momento propone la violencia como elemento positivo.

12 A pesar de rozar los diez años de su realización, el documental de Lorella Zanardo, Marco Malfi Chindemi y Cesare Cantù sobre el uso del cuerpo de la mujer en la televisión sigue tan actual como cuando se rodó, en 2009. La versión en español del vídeo está disponible en el blog /l corpo delle donne (<http://www.ilcorpodelledonne.net/version-en-espanol/>; última visita: 23.11.2017). 
mo diferente", en la segunda únicamente se reproduce el título, sin comentarios añadidos. Sin duda alguna, la editorial Versátil hace un uso más respetuoso de la imagen de la mujer. Una última consideración sobre el aspecto editorial de estas publicaciones es el precio: se va de los 10 a 20 euros para las versiones en papel, mientras que la versión en ebook cuesta menos de 6 euros, con lo cual se puede decir que se trata de un género económico y accesible, por lo menos en su formato digital.

Volviendo una vez más a la teorización de Michela Marzano sobre la pornografía, la filósofa detecta cómo, en la producción contemporánea, se ha pasado a nuevos estereotipos (Marzano 2012: 120): donde antes se buscaba la perfección formal de la imagen de la mujer (su cuerpo no podía mostrar imperfecciones), ahora se nota una demanda de "realidad", es decir de sujetos femeninos más comunes, más cotidianos, con cuerpos no canónicos y hasta se centra la atención en las peculiaridades de estos cuerpos. ${ }^{13}$ Sin quererlo, la narrativa de Carpallo reproduce un modelo muy parecido al de la industria porno, puesto que se propone contar las historias de mujeres comunes, "reales", con las que las lectoras puedan identificarse con más facilidad y, sin embargo, contribuye a la conservación de una serie de estereotipos dañinos para las mujeres. En una entrevista, a la pregunta sobre el porqué había decidido escribir El orgasmo de mi vida, la autora contesta:

Desde pequeña he querido escribir, por eso estudié periodismo. Y quería hablar de la sexualidad femenina porque no está nada explotada en la literatura erótica. En el libro hay cinco historias, más una de regalo, que tratan sobre sexo real. Es decir, situaciones reales con mujeres reales, no el típico argumento de encontrar al príncipe azul forrado de dinero. También se tratan temas algo peliagudos, como el de una mujer que está con un chaval de 17 años, amigo de su hijo, o el de una mujer heterosexual que vive en un mundo de hombres y que solo se encuentra liberada teniendo sexo con otra mujer. (S.f. 2014: online)

Temas como el de la madre que desea acostarse con el amigo de su hijo y viceversa no son propiamente un argumento nuevo en la producción erótica y porno; lo cual está testimoniado también por el fuerte interés que en los últimos años han cobrado las fantasías denominadas MILF y DILF. ${ }^{14}$ La historia de la mujer hetero que llega al "mejor orgasmo de su vida" acostándose con su amiga en una noche de borrachera no corresponde a un cambio ideológico, sino más bien a la nueva versión de otra fantasía bastante recurrente entre las mujeres heterosexuales, o sea ser "lesbiana por un día" (Fuentes 2006: online). Por último, la idea que subyace al propósito de "regalar" una historia nos lleva

\footnotetext{
13 En las estadísticas de 2016 elaboradas por Porn Hub, las primeras cinco categorías porno que recibieron más visitas en el año fueron: 1. Lesbian, 2. Teen (+18), 3. Ebony, 4. MILF y 5. Anal. En cambio, los cinco primeros términos más buscados fueron: 1. Lesbian, 2. Step mom, 3. MILF, 4. Teen y 5. Step sister (<http://www.pornhub.com/insights/2016-year-in-review>; última visita: 30.1.2017).

14 MILF: Mother I'(d) Like (to) Fuck; DILF: Dad I'(d) Like (to) Fuck.
} 
nuevamente al concepto de libro como producto, de literatura como recreo, sin más implicaciones.

Afirma Marzano que "el 'diálogo' entre imágenes y espectador puede establecerse solo en el caso en el que el autor respete tanto la 'madurez' mental de quien mira, como la vida interior y la independencia de los personajes que crea" (Marzano 2012: 119). Entonces, queda sin responder la pregunta sobre la "madurez mental" que se requiere al público al que se dirigen las obras de Carpallo, ya que la "vida interior y la independencia de los personajes" que aparecen en esas historias se quedan en la superficie. En la narrativa de esta autora, tanto las protagonistas como sus compañeros de aventuras se definen siempre y primeramente por sus características físicas. Para poner tan solo un ejemplo, la madre de Irene, Alejandra, disfruta "mirando" y "observando" a su hija y la describe en su belleza ("Es guapa, muy guapa, y no es porque sea mi hija. [...] En general, el físico, los ojos verdes, el pelo rubio y liso, la cara fina y, sobre todo, la forma de posar en las fotografías, es de mi hermana", Carpallo 2016: edición Kindle). El tema de la vista y de la imagen son una constante en la narrativa de Carpallo: los personajes viven a través de su descripción física, de su aspecto (agradable, siempre), que es lo primero. Como en las películas porno, son la apariencia y el marco lo que importa, no lo que hay detrás de ello, que solo sirve de relleno.

A pesar de los nobles propósitos que mueven a la autora (la liberación de la mujer a través de la educación sexual que estos libros vehiculan, la explotación de la sexualidad femenina en la literatura erótica, al parecer todavía poco desarrollada, etc.), los resultados aparecen como poco apreciables. A comienzos de los años 2000, afirmaba Virginie Despentes en su volumen Teoría King Kong que:

... solo los hombres imaginan el porno, lo ponen en escena, lo miran y sacan provecho; así el deseo femenino se ve sometido a la misma distorsión: debe pasar por la mirada masculina. Lentamente nos acostumbramos a la idea de un orgasmo femenino. [...] Pero, en lugar de ser una posibilidad, el orgasmo se ha vuelto un imperativo. Es necesario sentirse siempre incapaz de algo... (Despentes 2007: 87)

Las protagonistas de las obras de Carpallo sufren de esta nueva neurosis: su vida no puede ser feliz ni ellas son capaces de sentirse completas sin una vida sexual satisfactoria al cien por cien. En estas narraciones no hay espacio para la mediocritas, tanto las mujeres como los hombres tienen que mostrarse siempre a la altura de la situación y cumplir con las expectativas, sexuales y sentimentales. Así, pues, en estos libros no se aboga por un verdadero cambio, sino por la conservación de un sistema ideológico normalizador, que garantiza la prosecución no traumática de las estructuras del poder, ya que se da la idea de que, al tener la mujer el derecho a llegar al orgasmo, ha alcanzado su libertad. No es una casualidad que, como apuntaba Virginie Despentes, el porno tenga como elemento aglutinante de todas las decenas de géneros que lo componen, la censura (Despentes 2007: 83). Cuando en Francia se introduce, en los años 70, la censura de las películas porno, se hace por el éxito que el género tiene y no por una protesta popular o por un aumento de los casos de violencia de género. De acuerdo con 
lo que escribe Despentes, "el pueblo tiene que estarse quieto, sin duda demasiada lujuria podría interferir en su rendimiento en el trabajo" (Despentes 2007: 83). El porno, entonces, tiene una dimensión de lucha política que cierta narrativa erótica elude y no solo, ya que esta producción literaria participa en la conservación de la moral tranquilizadora hipernormativa. Lamentablemente, la narrativa que ha escrito hasta ahora Silvia C. Carpallo no sale de este perímetro. Quedan abiertas las apuestas para el futuro.

\section{OBRAS CITADAS}

Bernini, Lorenzo (2013): Apocalissi queer. Elementi di teoria antisociale. Pisa, ETS.

— (2015): Apocalipsis queer. Elementos de teoría antisocial. Madrid, Editorial Egales.

— (2017): Le teorie queer: un'introduzione. Milán, Mimesis.

Carpallo, Silvia C. (2014): El orgasmo de mi vida: un libro de sexo por y para todo tipo de mujeres. Barcelona, Lectio, edición Kindle.

- (2015): Decirte adiós con un te quiero. Barcelona, Versátil.

— (2016a): "Mujeres y pornografía, ¿delante o detrás de la cámara?", Blog Eros, El País, 30 de noviembre; accesible en <http://blogs.elpais.com/eros/2016/11/mujeresy-pornograf\%C3\%ADa-delante-o-detras-de-la-camara.html> [última visita: 27.1.2017].

(2016b): Si el amor te dijo "no" pregúntale otra vez. Barcelona, Versátil, edición Kindle.

_ y La Vie en Rouge (2013): Cincuenta escenarios para desatar tu pasión. Barcelona, Grijalbo.

Cavarero, Adriana (1987): "Per una teoria della differenza sessuale". En Adriana Cavarero et al. (eds.): Diotima. Il pensiero della differenza sessuale. Milán, La Tartaruga, pp. 43-79.

_ (2002): "Il pensiero femminista. Un approccio teoretico". En Adriana Cavarero y Franco Restaino (eds.): Le filosofie femministe. Milán, Bruno Mondadori, pp. 78-115.

Ciuraru, Carmela (2012): Nom de Plume: A (Secret) History of Pseudonyms. Nueva York, Harper Perennial.

Despentes, Virginie (2007): Teoría King Kong. Barcelona, UHF.

Fuentes, Sonsoles (2006): "Lesbiana por un día", Woman, 2 de junio; accesible en <http:// www.woman.es/lifestyle/sexo_y_pareja/lesbiana-por-un-dia> [última visita: 30.1.2017].

Galliani, Emiliana (2011): "La pornografia come atto linguistico: dimensione illocutoria e perlocutoria del performativo", Esercizi Filosofici, n. ${ }^{\circ}$ 6, pp. 251-265.

Illouz, Eva (2014): Erotismo de autoayuda: Cincuenta sombras de Grey y el nuevo orden romántico. Buenos Aires, Katz.

León, Sergio (2015): "Silvia C. Carpallo: Hay que entender que el porno es ficción y no dejar que sea la referencia en nuestro sexo", El Público, 6 de diciembre; accesible en <http://www.publico.es/sociedad/silvia-c-carpallo-hay-entender.html> [última visita: 27.1.2017].

Marzano, Michela (2012): La fine del desiderio. Riflessioni sulla pornografia. Milán, Mondadori. 
Núñez Florencio, Rafael (2013): "A la sombra de Grey: el nuevo boom del libro erótico", Revista Internacional del Libro, Digitalización y Bibliotecas, vol. 1, n. ${ }^{\circ} 2$, pp. $27-36$.

Preciado, Beatriz [Paul B.] (2002): Manifiesto contra-sexual. Prácticas subversivas de identidad sexual. Madrid, Editorial Opera Prima.

Propp, Vladimir (1974): Morfología del cuento. Madrid, Fundamentos.

Restaino, Franco (2002): "Il pensiero femminista. Una storia possibile". En Adriana Cavarero y Franco Restaino (eds.): Le filosofie femministe. Milán, Bruno Mondadori, pp. 3-77.

S.f. (2014): "La gente se educa sexualmente viendo pornografía. Entrevista con Silvia C. Carpallo, escritora erótica", Clouderview; accesible en <http://clouderview.com/entrevista/presentacion/48?nombre=silvia-carpallo> [última visita: 27.1.2017].

Sarracino, Carmine, y Scott, Kevin M. (2008): The Porning of America: The Rise of Porn Culture, what it Means, and where We Go from Here. Boston, Beacon Press.

Zanardo, Lorella (2010): Il corpo delle donne. Milán, Mondadori. 